\title{
CARACTERIZAÇÃO QUÍMICA DO BAGAÇO DE MALTE E AVALIAÇÃO DO SEU POTENCIAL PARA OBTENÇÃO DE PRODUTOS DE VALOR AGREGADO
}

\section{CHEMICAL CHARACTERIZATION OF BREWER'S SPENT GRAINS AND EVALUATION OF ITS POTENTIAL FOR OBTAINING VALUE-ADDED PRODUCTS}

\author{
M. M. MASSARDI ${ }^{1 *}$, R. M. M. MASSINI ${ }^{1}$, D. J. SILVA ${ }^{1}$ \\ ${ }^{1}$ Universidade Federal de Viçosa, Departamento de Química, Viçosa, Minas Gerais, Brasil
}

*Autor para correspondência. Universidade Federal de Viçosa, Departamento de Química, Viçosa, MG, Brasil, Telefone: +55 32999258139

Endereço de e-mail: mm.massardi@gmail.com (M. M. Massardi)

I N F O R M A Ç Õ E S

Article history:

Received 2019-12-13

Accepted 2020-02-20

Available online 2020-02-20

\section{palavras-chave}

Biomassa lignocelulósica;

Proteínas;

Biorrefinaria;

Produtos químicos.

keywords

Lignocellulosic biomass;

Protein;

Biorefinary;

Chemical products.
R E S U M O

O bagaço de malte é o principal resíduo da indústria cervejeira. Frente a isso, surge a necessidade de avaliar diferentes formas de reaproveitamento deste material. O presente estudo teve como objetivos principais caracterizar esta biomassa e avaliar as possibilidades para seu reaproveitamento como matéria-prima para produtos de valor agregado. Foram obtidos teores de 29,92\% de hemiceluloses, 21,16\% de proteínas, 20,80\% de lignina total, $15,99 \%$ de celulose, $8,33 \%$ de extrativos e $3,76 \%$ de cinzas no material. A composição química encontrada possibilita diversas aplicações deste resíduo como matéria-prima para obtenção de produtos de maior valor agregado. Estas aplicações estão relacionadas aos altos teores de fibras lignocelulósicas e de proteínas, sendo as principais: produção de etanol de segunda geração, de carvão hidrotérmico, de ácido lático, de HMF e de produtos para nutrição humana.

\section{A B S T R A C T}

Brewer's spent grains are the major residue on beer industry. Thus, it is necessary to evaluate different ways for its reuse. This study aimed the characterization of this biomass and the evaluation of possibilities to reuse it as raw material for value-added products. Were obtained, on dry basis: $29.92 \%$ hemicellulose, $21.16 \%$ protein, $20.80 \%$ total lignin, $15.99 \%$ cellulose, $8.33 \%$ extractives and $3.76 \%$ ash in the material. The composition found enable various uses of this residue as raw material for obtaining value-added products. The uses are related to its high content of lignocellulosic fibers and protein, and the main are: second-generation ethanol, hydrothermal coal, lactic acid, HMF and products for human nutrition. 


\section{INTRODUÇÃO}

A cerveja, uma das bebidas mais produzidas e consumidas no mundo, caracteriza-se por ser uma bebida fermentada e de baixo teor alcoólico. Seu principal ingrediente, o malte de cevada, é um material rico em amido que fornece açúcares redutíveis que são substratos para as leveduras produzirem etanol.

Considerando os últimos dados, compilados e disponibilizados pela Associação Brasileira da Indústria da Cerveja, o Brasil produziu 14,1 bilhões de litros desta bebida em 2016, contribuindo com $1,6 \%$ do PIB do ano no país, empregando mais de 2,7 milhões de trabalhadores e gerando 21 bilhões de reais em impostos, o que demonstra o tamanho e a força desse ramo no cenário da indústria nacional (CERVBRASIL, 2017). O Brasil atuou como o terceiro maior produtor mundial da bebida no ano, atrás somente da China (41,4 bilhões de litros) e dos Estados Unidos (22,1 bilhões de litros) (KIRIN HOLDINGS COMPANY, 2017). O mercado cervejeiro no país vem evoluindo de forma exponencial nos últimos anos, fato este devido, principalmente, ao grande movimento para criação de micro cervejarias: em 2013 havia, aproximadamente, 200 fábricas registradas, enquanto que, em 2018, esse número chegou a 889 (MARCUSSO; MÜLLER, 2019).

Um revés à alta produção é a grande quantidade de resíduos sólidos e líquidos gerados nas indústrias. O principal e mais abundante é o bagaço de malte, ou BSG (sigla do inglês “brewer's spent grain”), gerado na etapa de mosturação, correspondendo a $85 \%$ de todos os resíduos gerados (REINOLD, 1997). Como ilustração, na fabricação de 100 litros de cerveja, são gerados $20 \mathrm{~kg}$ do bagaço com $70 \%$ a $80 \%$ de umidade (KUNZE, 2014), isso equivale a uma produção média de 2,82 milhões de toneladas do material por ano no Brasil, ou, em média, 0,71 milhões de toneladas do resíduo seco, se for considerada a produção total de cerveja em 2016. A maior parte deste montante foi destinada à alimentação animal (bovinos, suínos, aves e caprinos), e há pesquisas que avaliaram o potencial dessa adição à dieta dos mesmos (ALIYU; BALA, 2011; GONÇALVES et al., 2009; MUSSATTO et al., 2006; PARPINELLI, 2016). Porém, apesar das vantagens nutricionais, este uso tem apresentado problemas para os produtores rurais, relacionados à dificuldade de armazenamento correto e ao alto teor de umidade. A contaminação deste material por microrganismos, acentuada pelos fatores citados, tem ocasionado enfermidades em bovinos, como intoxicação por fungos e micotoxinas, acidose ruminal e botulismo (BRUST et al., 2015). Aliado à dificuldade de transporte e à possibilidade de transformar o bagaço em produtos de maior valor agregado, a tendência é de redução dessa aplicação e de estudo de novas formas de reaproveitamento.

A composição do bagaço de malte é diversa, desde que é resultante da variedade de tipos comerciais e processos de fabricação de cerveja existentes. Em geral, tem-se: celulose $(16,8 \%$ - 20,6\%), hemiceluloses $(18,4 \%-28,4 \%)$, lignina $(9,9 \%$ - 27,8\%), proteínas $(15,3 \%-26,6 \%)$, extrativos $(5,2 \%-5,8 \%)$ e cinzas $(2,7 \%$ - 4,6\%) (MUSSATTO; ROBERTO, 2006; QIN et

\section{al., 2018; WILKINSON et al., 2014).}

Entre as hemiceluloses, os polímeros constituintes mais encontrados no bagaço de malte são xilana e arabinana, formados pelos açúcares xilose e arabinose, respectivamente (MUSSATTO; ROBERTO, 2006; PINHEIRO et al., 2019; QIN et al., 2018). Já entre as proteínas, destacam-se as hordeínas, compondo até $60 \%$ das proteínas do grão (LINSKENS; JACKSON, 1988; MOLINA-CANO et al., 2001). Estas são proteínas de reserva que não são extraídas na mosturação, uma vez que apresentam solubilidade apenas em soluções alcoólicas de concentração 70\% a 80\% v/v (MOLINA-CANO et al., 2001; SGARBIERI, 1996).

Dessa forma, o objetivo deste trabalho foi determinar a composição química do bagaço de malte oriundo de micro cervejaria e propor alternativas para o reaproveitamento deste material, transformando-o em produtos com maior valor agregado.

\section{MATERIAL E MÉTODOS}

O bagaço de malte utilizado, de tipo pilsen, foi fornecido pela cervejaria Wegas Bier, situada em Cajuri - MG. O material foi coletado logo após a filtração do mosto e armazenado sob refrigeração por um dia, quando foi manipulado. Foi realizada uma prensagem manual do bagaço com objetivo de retirar o excesso de água, seguido de secagem em estufa (Nova Ética, $400 \mathrm{ND}$ ) a $60 \pm 3{ }^{\circ} \mathrm{C}$ até possuir teor a.s. (absolutamente seco) superior a $90 \%$.

Após seco, o material passou por moagem em moinho tipo Wiley e foi classificado em sistema de peneiras vibratórias Bertel utilizando mesh 35, 42, 48 e 60 . As frações retidas nas peneiras de mesh 48 e 60 (material com granulometria entre 42 e $60 \mathrm{mesh}$ ) foram misturadas e utilizadas nos procedimentos de caracterização. A escolha desses valores foi feita por conta da especificidade de alguns métodos de determinação quanto ao tamanho das partículas a serem analisadas, devendo as mesmas apresentarem granulometria entre 40 e 60 mesh.

\subsection{Determinação do teor de umidade}

A determinação de umidade do material após a secagem em estufa e em cada procedimento da caracterização química foi realizada em um analisador de umidade (Shimadzu, MOC63 UniBloc), utilizando 0,5 a 1,0 g de amostra por análise.

\subsection{Determinação do teor de proteínas}

Para determinação do teor de proteínas do bagaço de malte, foi utilizado o método de Kjeldahl, adaptado do Laboratório Nacional Agropecuário, código MET POA/11/02/01 (ANDRADE et al., 2013). Este método quantifica o teor de nitrogênio total na amostra, sendo este convertido em teor de proteínas utilizando fator de conversão adequado. Para o bagaço de malte, o fator utilizado foi 6,25, assim como nos estudos realizados por Pinheiro et al. (2019), Wilkinson et al. (2014) e Mussatto e Roberto (2006).

Foram pesados, em triplicata, aproximadamente $0,5 \mathrm{~g}$ de amostra em papel livre de nitrogênio, que foi colocado em tubo 
de digestão. Para o ensaio em branco, foi utilizado apenas o papel. Foram adicionados $10 \mathrm{~mL}$ de mistura contendo ácido sulfúrico $98 \% \mathrm{v} / \mathrm{v}$, sulfato de cobre e sulfato de potássio, e, então, os tubos foram aquecidos, gradativamente, permanecendo por 15 minutos a cada $50{ }^{\circ} \mathrm{C}$. Após atingir 400 ${ }^{\circ} \mathrm{C}$, a amostra foi digerida até apresentar aspecto límpido de cor azul-esverdeada. Após a digestão, os tubos foram retirados do digestor, colocados sobre um suporte para que fossem resfriados lentamente, sendo adicionados $10 \mathrm{~mL}$ de água destilada para evitar a cristalização.

A destilação foi realizada em destilador de nitrogênio (Tecnal, TE-036/1). Foi acoplado ao aparelho frasco erlenmeyer contendo $10 \mathrm{~mL}$ de solução de ácido bórico $4 \% \mathrm{~m} / \mathrm{v}$ e foi adicionada solução de $\mathrm{NaOH} 50 \% \mathrm{~m} / \mathrm{v}$ até que o conteúdo do tubo ficasse negro, momento em que foi ligada a alimentação de vapor de água. Após completa destilação da amônia, o frasco coletor foi titulado com solução $0,1 \mathrm{M}$ de ácido clorídrico utilizando vermelho de metila como indicador.

Para o cálculo do teor de proteínas, foi utilizada a Equação 1 .

$$
T P(\%)=\frac{\left(V_{L}-V_{B}\right) * N * 0,014 * F}{M_{a} * T A S} * 100
$$

Em que: $\mathrm{TP}=$ teor de proteínas, $\% ; \mathrm{V}_{\mathrm{B}}=$ volume gasto de $\mathrm{HCl} \mathrm{0,1} \mathrm{M} \mathrm{na} \mathrm{titulação} \mathrm{em} \mathrm{branco,} \mathrm{mL} ; \mathrm{V}_{\mathrm{L}}=$ volume gasto de $\mathrm{HCl}$ 0,1 M na titulação da amostra, $\mathrm{mL} ; \mathrm{N}=$ concentração molar do HCL usado na titulação, mol $\mathrm{L}^{-1} ; \mathrm{F}=$ fator de conversão; TAS = teor a.s.; $\mathrm{M}_{\mathrm{a}}=$ massa de amostra utilizada, $\mathrm{g}$.

\subsection{Determinação do teor de cinzas}

O teor de cinzas do material foi determinado a partir da metodologia NREL/TP-510-42622 (SLUITER et al., 2008a). Três amostras de 1,0 g do bagaço de malte moído com granulometria entre 42 e 60 mesh foram inseridas em três cadinhos de porcelana previamente tarados em mufla (Jung, 0612) por $2 \mathrm{~h}$ a $550 \pm 25^{\circ} \mathrm{C}$, dessecados à temperatura ambiente e pesados em balança analítica (TKS, FA2004C), com precisão de $0,0001 \mathrm{~g}$.

Os cadinhos contendo o material foram inseridos na mufla a $550 \pm 25{ }^{\circ} \mathrm{C}$ por $8 \mathrm{~h}$ até completa calcinação. Em seguida, foram colocados em dessecador por $1 \mathrm{~h}$ e, então, pesados para determinação da massa de amostra remanescente, referente aos componentes minerais (cinzas) do material, sendo seu teor determinado pela Equação 2 .

$$
T C(\%)=\frac{m_{2}-m_{1}}{M_{a} * T A S} * 100
$$

Em que: $\mathrm{TC}=$ teor de cinzas da amostra, $\% ; \mathrm{m}_{1}=$ massa do cadinho tarado, $\mathrm{g} ; \mathrm{m}_{2}=$ massa do cadinho com amostra calcinada, g; TAS = teor a.s.; $\mathrm{M}_{\mathrm{a}}=$ massa de amostra, $\mathrm{g}$.

\subsection{Determinação do teor de extrativos}

A metodologia utilizada na determinação do teor de extrativos do material foi adaptada da metodologia NREL/TP510-42619 (SLUITER et al., 2008b). Foi pesada, em balança analítica (Shimadzu, ATY224 UniBloc), com precisão de 0,0001 g, uma amostra de 2,6 g do bagaço de malte moído com granulometria entre 42 e 60 mesh que foi inserida em cartucho de papel filtro para extração em aparato soxhlet. Foram utilizados $150 \mathrm{~mL}$ de solução de etanol $80 \% \mathrm{v} / \mathrm{v}$ como solvente extrator, que foram inseridos em balão de fundo chato de 250
$\mathrm{mL}$ previamente seco em estufa a $105 \pm 3{ }^{\circ} \mathrm{C}$ por $2 \mathrm{~h}$. $\mathrm{O}$ balão foi colocado em manta de aquecimento, o aparato foi montado e o procedimento de extração ocorreu por $8 \mathrm{~h}$, contabilizando a partir do primeiro ciclo de viragem do solvente pelo sifão, totalizando 24 ciclos (três por hora).

Passado o período de extração, o balão contendo solvente e extrativos foi colocado novamente na estufa a $105 \pm 3{ }^{\circ} \mathrm{C}$ para retirada do solvente até massa constante. A massa final foi anotada e o teor de extrativos foi determinado a partir da Equação 3. O procedimento foi conduzido em duplicata.

$$
T E(\%)=\frac{m_{2}-m_{1}}{M_{a} * T A S} * 100
$$

Em que: $\mathrm{TE}=$ teor de extrativos da amostra, \%; $\mathrm{m}_{1}=$ massa do balão tarado, $\mathrm{g} ; \mathrm{m}_{2}=$ massa do balão com extrativos e sem solvente, $\mathrm{g}$; TAS = teor a.s.; $\mathrm{M}_{\mathrm{a}}=$ massa de amostra, $\mathrm{g}$.

O procedimento utilizado para extração, porém, também retira proteínas da amostra, principalmente as hordeínas, as quais são solúveis em etanol 70 a 80\% (SGARBIERI, 1996). Desta forma, foi realizada uma análise Kjeldahl no material sem extrativos, assim como detalhado no item 4.2.2, para possibilitar a correção do teor de extrativos do material e o cálculo do teor real, utilizando a Equação 4.

$$
T R E(\%)=T E-(T P-T P S E)
$$

Em que: TRE $=$ teor real de extrativos da amostra, \%; TE $=$ teor de extrativos contendo proteínas, $\% ; \mathrm{TP}=$ teor de proteínas do material cru, \%; TPSE $=$ teor de proteínas no material livre de extrativos, $\%$.

\subsection{Determinação do teor de lignina insolúvel}

O método utilizado para determinação da lignina insolúvel do bagaço de malte foi o método Klason, descrito por Gomide e Demuner (1986), com uma metodologia adaptada à proposta pela TAPPI T222 os-74. Esta adaptação foi feita buscando-se a utilização de uma menor massa de amostra e a otimização do tempo de processo.

Foram pesadas 3 alíquotas (previamente secas e com teor a. s. determinado) de cerca de 0,3 g do material livre de extrativos, diretamente em 3 tubos de ensaios reacionais e, em seguida, 3,0 mL de ácido sulfúrico $72 \% \mathrm{v} / \mathrm{v}$ resfriado foram adicionados em cada um. Os tubos foram inseridos em um suporte e colocados em banho termostático com recirculação (Matoli, 170M020), controlado a $30{ }^{\circ} \mathrm{C}$ por 60 minutos. O conteúdo dos frascos foi agitado manualmente a cada 10 minutos utilizando bastonetes de vidro para homogeneização do meio reacional, buscando promover a hidrólise completa.

Após decorridos os 60 minutos, os hidrolisados foram transferidos para frascos de tipo penicilina, havendo seguinte adição de 84,0 $\mathrm{mL}$ de água destilada em cada um. Os frascos foram fechados com tampa de borracha e lacrados com lacre de alumínio para vedação hermética. Em seguida, foram inseridos em reator pressurizado, onde foi feita a reação a, aproximadamente, $120^{\circ} \mathrm{C}$ e por 50 minutos.

$\mathrm{Na}$ sequência, foi feita a filtragem a vácuo dos hidrolisados em cadinhos de vidro sinterizado com manta de amianto de $2 \mathrm{~g}$ preparada a partir de suspensão. Eles foram previamente secos em estufa Nova Ética a $105 \pm 3{ }^{\circ} \mathrm{C}$ até massa constante. Os sólidos presentes em cada cadinho foram lavados com água destilada para a remoção do ácido residual durante a filtragem e, em seguida, os cadinhos foram levados à estufa para 
secagem até massa constante a $105 \pm 3{ }^{\circ} \mathrm{C}$ e pesados, sendo a massa obtida referente à lignina insolúvel da amostra. Os filtrados tiveram seus volumes completados para $500 \mathrm{~mL}$ e foram armazenados em frascos âmbar, sendo utilizados para determinação dos teores de lignina solúvel, de celulose e de hemiceluloses presentes.

O teor de lignina insolúvel presente na amostra seca foi determinado pela Equação 5.

$$
\operatorname{TLI}(\%)=\frac{\left(\mathrm{m}_{2}-\mathrm{m}_{1}\right) *(1-T E)}{\mathrm{M}_{\mathrm{a}} * \mathrm{TAS}} * 100
$$

Em que: TLI = teor de lignina insolúvel da amostra, \%; $\mathrm{m}_{1}=$ massa do cadinho seco antes da filtragem, $\mathrm{g} ; \mathrm{m}_{2}=$ massa do cadinho pós filtragem e secagem (contendo a lignina insolúvel), $\mathrm{g} ; \mathrm{M}_{\mathrm{a}}=$ massa de amostra livre de extrativos, $\mathrm{g}$; TAS $=$ teor a.s.; TE $=$ teor de extrativos.

\subsection{Determinação do teor de lignina solúvel}

O teor de lignina solúvel da amostra foi determinado a partir da utilização da metodologia proposta por Goldschmid (1971). Os filtrados obtidos na etapa de determinação do teor de lignina solúvel tiveram suas absorbâncias analisadas em espectrofotômetro UV-vis Agilent 8453 nos comprimentos de onda de 215 e $280 \mathrm{~nm}$, utilizando solução de ácido sulfúrico $0,5 \% \mathrm{v} / \mathrm{v}$ como "branco".

Os valores de absorbância obtidos foram utilizados na Equação 6 para determinação dos resultados.

$$
T L S(\%)=\frac{\left[4,538 * A_{215}-A_{280}\right] *(1-T E) * 100}{2 * 300 * M_{a} * T A S}
$$

Em que: TLS = teor de lignina solúvel, \%; $\mathrm{A}_{215}=$ absorbância obtida no comprimento de onda de $215 \mathrm{~nm} ; \mathrm{A}_{280}=$ absorbância obtida no comprimento de onda de $280 \mathrm{~nm} ; \mathrm{M}_{\mathrm{a}}=$ massa de amostra livre de extrativos utilizada, g; TAS = teor a.s.; $\mathrm{TE}=$ teor de extrativos.

\subsection{Determinação dos teores de celulose e de hemiceluloses}

As determinações dos teores de celulose e de hemiceluloses seguiram metodologia adaptada à proposta na NREL/TP-510-42618 (SLUITER et al., 2012). Estas foram conduzidas a partir de análise em cromatografia líquida de alta eficiência (HPLC), no cromatógrafo Shimadzu modelo Prominence, utilizando o hidrolisado filtrado obtido previamente na determinação do teor de lignina insolúvel da amostra (método Klason). Foram quantificados os monômeros glicose, xilose e arabinose. As condições de análise foram: coluna Phenomenex Rezex RPM-Monossacharide, fase estacionária de chumbo, fase móvel $85 \%$ água, $15 \%$ acetonitrila, temperatura $80{ }^{\circ} \mathrm{C}$, fluxo $0,85 \mathrm{~mL} \mathrm{~min}{ }^{-1}$, por 18 minutos, com quantificação por detector evaporativo com espalhamento de luz (ELSD).

No cálculo do teor destes constituintes, levou-se em consideração a diluição feita no processo da quantificação de lignina insolúvel, como demonstrado no Item 2.5.Os valores reais foram calculados através da Equação 7.

$$
T M(\%)=\frac{C M_{H P L C} * V * F D *(1-T E)}{M_{a} * T A S} * 100
$$

Em que: $\mathrm{TM}=$ teor do monômero, \%; $\mathrm{TE}=$ teor de extrativos; $\mathrm{CM}_{\mathrm{HPLC}}=$ concentração do monômero obtida no HPLC, $\mathrm{mg} \mathrm{mL}^{-1} ; \mathrm{M}_{\mathrm{a}}=$ massa de amostra livre de extrativos, $\mathrm{mg}$; $\mathrm{V}=$ volume de hidrolisado, $\mathrm{mL} ; \mathrm{TAS}=$ teor a.s.; $\mathrm{FD}=$ fator de diluição.

Para converter os teores de monômeros nos teores de seus respectivos polímeros, foi utilizada a Equação $8 \mathrm{com}$ o fator de correção. Para os teores de celulose, de xilana e de arabinana, foram considerados os teores de glicose, de xilose e de arabinose, respectivamente. No cálculo do teor de celulose, o fator é 0,9 , enquanto, para xilana e arabinana, este é 0,88 . Além disso, o teor de hemiceluloses é considerado como a soma dos teores de xilana e de arabinana, seus principais polímeros constituintes.

$$
T P L(\%)=T M * F C
$$

Em que: $\mathrm{TPL}=$ teor do polímero, \%; $\mathrm{TM}=$ teor do monômero, \%; FC = fator de correção para cada polímero.

\section{RESULTADOS E DISCUSSÃO}

Os resultados obtidos para a composição química do bagaço de malte são apresentados na Tabela 1. A lignina total é a soma entre lignina insolúvel (Klason) e solúvel, enquanto o teor de hemiceluloses é considerado como a soma entre os teores de xilana e de arabinana. Todos os teores foram calculados em base seca.

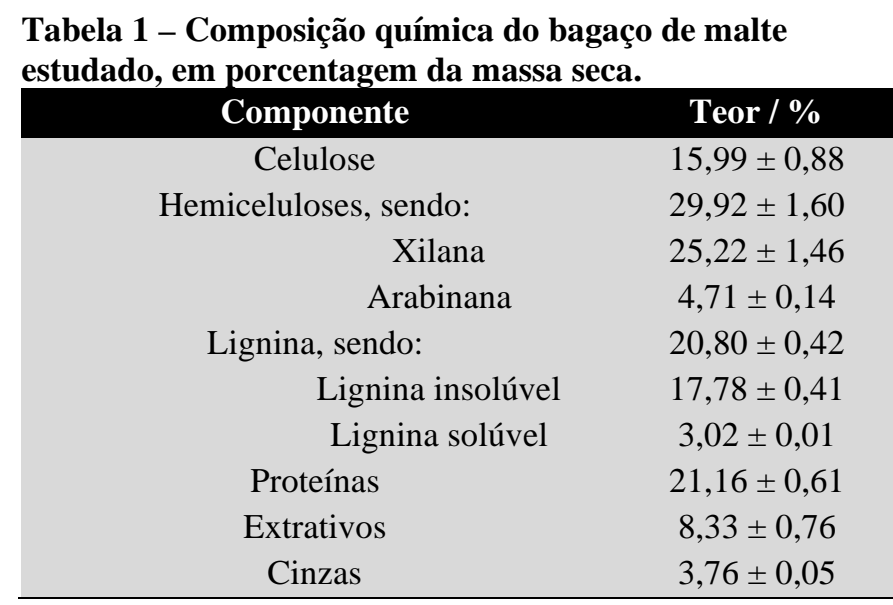

Observa-se que o material possui composição dentro da faixa encontrada na literatura. O teor de celulose $(15,99 \%)$ é próximo aos valores encontrados por Mussatto e Roberto (2006) e por Wilkinson et al. (2014), sendo estes $16,78 \%$ e 19,2\%, respectivamente. Para a hemicelulose, foi obtido teor de 29,92\%, semelhante aos de Mussatto e Roberto (2006), 28,42\%, e de Qin et al. (2018), 25,97\%. Apesar das grandes divergências na literatura, o teor de lignina encontrado $(20,80 \%)$ foi similar ao de Qin et al. (2018), 19,57\%. Os teores de proteínas $(21,16 \%)$ e de cinzas $(3,76 \%)$ foram próximos aos de Pinheiro et al. (2019), $14,3 \%$ a $20,2 \%$ e $1,9 \%$ a 3,7\%, e Qin et al. (2018), $22,44 \%$ e $3,54 \%$, respectivamente. Já o teor de extrativos $(8,33 \%)$ se aproximou dos valores encontrados por Mussatto e Roberto (2006), 5,82\%, por Wilkinson et al. (2014), 5,2\%, e por Qin et al. (2018), 5,30\%. As diferenças entre os resultados encontrados podem ser devidas, principalmente, à diversidade de tipos de malte e receitas cervejeiras, mas também, em menor parte, às metodologias de análise utilizadas por estes autores, que diferem em virtude da evolução dos métodos de quantificação e dos equipamentos, dos reagentes e dos instrumentos disponíveis. 
A soma dos teores encontrados para cada componente na caracterização química resultou em um total de 99,96\%, indicando que os procedimentos realizados foram eficientes para quantificar todas as frações do material estudado. Erros experimentais podem estar relacionados à imprecisão de equipamentos e de instrumentos e à presença de impurezas em reagentes, além de erros aleatórios ocorridos durante a realização dos experimentos.

\section{USO DO BAGAÇO DE MALTE COMO MATÉRIA-PRIMA PARA OBTENÇÃO DE PRODUTOS DE MAIOR VALOR AGREGADO}

A partir dos resultados encontrados para a composição química do bagaço de malte, é possível propor alternativas para o reaproveitamento deste como matéria-prima para obtenção de produtos com maior valor agregado. Dentre os componentes do material, destacam-se as frações que compõem os carboidratos $(15,99 \%$ de celulose, $29,92 \%$ de hemiceluloses) e as que compõem as proteínas $(21,16 \%)$ que apresentam ampla gama de aplicações na indústria.

\subsection{Etanol de segunda geração}

A produção de etanol a partir de biomassa lignocelulósica, também chamado de etanol de segunda geração ou etanol celulósico, já é um processo estudado amplamente e aplicado industrialmente para materiais como os resíduos da cana-de-açúcar. No Brasil, a fábrica de etanol celulósico da Granbio, em Alagoas, detém uma produção de 60 milhões de litros por ano (BIOFLEX, 2011). A da Raízen produziu sete milhões de litros em 2016 e a previsão é que a planta opere em capacidade máxima, de 40 milhões de litros, até 2020 (GOMES, 2018).

Na produção deste biocombustível, a biomassa passa por processos que hidrolisam os polímeros constituintes da matriz lignocelulósica, especialmente celulose e hemiceluloses, formando monossacarídeos fermentescíveis. Para que isto seja possível, o processo é dividido em etapas, sendo a primeira o pré-tratamento, que extrai as hemiceluloses e expor as fibras de celulose, e a segunda a hidrólise enzimática, que converte a celulose polimerizada em monômeros de glicose (DRAPCHO et al., 2008). A sequência comumente encontrada neste procedimento é apresentada na Figura 1.

Durante os processos de pré-tratamento e de hidrólise, uma etapa determinante e indesejada é a formação de inibidores da fermentação. Estes compostos são gerados a partir da degradação dos componentes encontrados na matriz lignocelulósica e são metabolizados pelos microrganismos fermentadores, formando produtos tóxicos que retardam a fase lag e reduzem o rendimento do processo (BOYER et al., 1992; PALMQVIST; HAHN-HÄGERDAL, 2000).

Para o bagaço de malte, este processo ainda não é realizado comercialmente, porém diversos estudos já abordam este tema, buscando otimizar as condições de pré-tratamento e hidrólise do material. Wilkinson et al. (2014) avaliaram o efeito do pré-tratamento hidrotérmico catalisado na liberação de açúcares e na formação de inibidores. Foram estudados diversos ácidos e bases diluídos a $121{ }^{\circ} \mathrm{C}$ por 30 minutos, com carregamento de sólidos $25 \%$ massa/volume, além de posterior sacarificação enzimática.

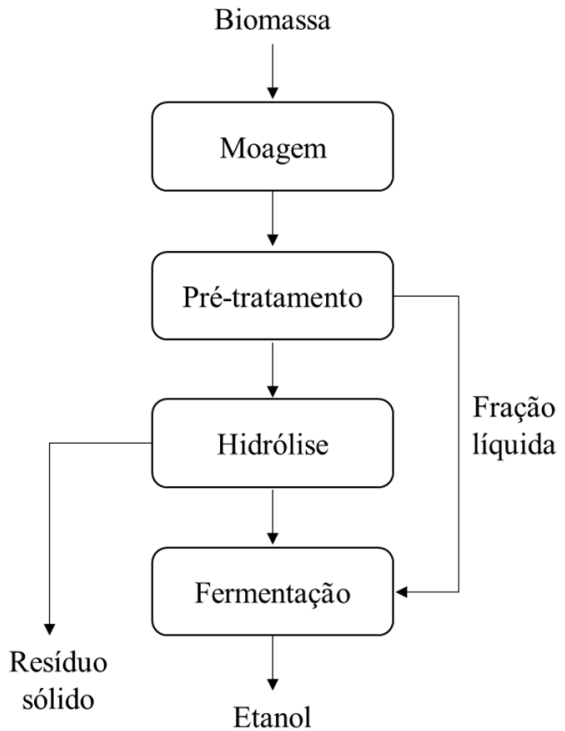

\section{Figura 1 - Processo produtivo do etanol celulósico.}

Fonte: Adaptado de DRAPCHO et al., 2008.

Os melhores resultados foram alcançados para os ácidos clorídrico e sulfúrico, porém com formação superior à obtida com outros catalisadores de $\operatorname{HMF}\left(0,23 \mathrm{~g} \mathrm{~L}^{-1}\right.$ no tratamento com ácido sulfúrico e $0,44 \mathrm{~g} \mathrm{~L}^{-1}$ no tratamento com ácido clorídrico) e de furfural $\left(0,46 \mathrm{~g} \mathrm{~L}^{-1}\right.$ no tratamento com ácido sulfúrico e 0,41 $\mathrm{g} \mathrm{L}^{-1}$ no tratamento com ácido clorídrico). Ainda assim foram obtidos rendimentos próximos a $70 \%$ do etanol teórico.

Pinheiro et al. (2019) focaram seu estudo na razão massa/volume do carregamento de sólidos, utilizando prétratamento hidrotérmico sem catalisador (água, $170{ }^{\circ} \mathrm{C}, 5$ minutos) e sacarificação enzimática. $\mathrm{O}$ melhor cenário apresentado foi para carga de $25 \%$ sólidos, fornecendo um rendimento de $94 \%$ em etanol.

Ravindran et Al. (2018) avaliaram as diferentes formas de pré-tratamento buscando encontrar o melhor em termos de extração dos açúcares do bagaço. Para isso, foram comparados os pré-tratamentos utilizando ácido diluído, explosão a vapor, explosão de fibra por amônia, cloreto férrico, Organosolv e alcalino com micro-ondas. Os melhores resultados, em termos de açúcares redutores, foram encontrados para o tratamento alcalino com micro-ondas (228,78 $\left.\mathrm{mg} \mathrm{g}^{-1}\right)$, seguido da explosão de fibra por amônia $\left(211,2 \mathrm{mg} \mathrm{g}^{-1}\right)$ e do ácido diluído $(208,8 \mathrm{mg}$ $\left.\mathrm{g}^{-1}\right)$ que, apesar de bom rendimento, provocou também a formação de furfural $\left(17 \mathrm{mg} \mathrm{g}^{-1}\right)$.

Dessa forma, por ser um material com aproximadamente $46 \%$ de polímeros (celulose e hemicelulose) que podem ser convertidos em açúcares fermentescíveis, é possível considerar o bagaço de malte como sendo uma matériaprima potencial para etanol de segunda geração.

\subsection{Carvão hidrotérmico}

A carbonização hidrotérmica é um processo que converte a biomassa lignocelulósica em matéria rica em carbono, os chamados carvões hidrotérmicos. Estes produtos possuem elevado poder calorífico, sendo utilizados normalmente como biocombustíveis, como adsorventes em biorremediação e para melhoramento de solo (KHAN et al., 2019; POERSCHMANN et al., 2015).

O processo consiste no uso de temperaturas e pressões 
elevadas, geralmente utilizando água como solvente e catalisadores ácidos ou básicos. Para maximizar a produção de sólidos ricos em carbono, as condições devem ser subcríticas, com temperatura entre $180{ }^{\circ} \mathrm{C}$ e $260{ }^{\circ} \mathrm{C}$. Nessa situação, as propriedades da água são modificadas e possibilitam uma série de reações que provocam a formação do produto desejado (KHAN et al., 2019). O mecanismo proposto por Khan et al. (2018), que estudaram a carbonização hidrotérmica da madeira de seringueira, é iniciado pela hidrólise e desidratação da celulose, das hemiceluloses, da lignina e de monômeros constituintes, gerando compostos furânicos e fenólicos, que são polimerizados formando uma rede aromática de carbono, que se organizam em forma de microesferas de carbono, o principal produto da carbonização.

Para o bagaço de malte, estudos avaliaram a carbonização hidrotérmica em condições subcríticas, com temperaturas entre $200^{\circ} \mathrm{C} \mathrm{e} 240^{\circ} \mathrm{C}$, tempo reacional de 14 horas e catalisador ácido cítrico, obtendo resultados que mostram a viabilidade de uso deste material como matéria-prima para o processo (POERSCHMANN et al., 2014, 2015).

A separação e análise dos produtos obtidos na fase líquida evidenciou a formação de ácidos graxos, ácidos carboxílicos de cadeia curta, fenóis, ácidos carboxílicos aromáticos e outros, indicando a possibilidade de uso desta fração como plataforma química para síntese de compostos de interesse industrial (POERSCHMANN et al., 2015).

Por outro lado, o biocarvão obtido apresentou cerca de dois terços do carbono orgânico presente no bagaço de malte, formando um produto com propriedades adsorventes $\mathrm{e}$ energéticas. As análises calorimétricas mostraram que houve densificação da energia no material, que possui maior poder calorífico quando comparado ao substrato (1,35 a 1,43 vezes), devido à desoxigenação da biomassa (POERSCHMANN et al., 2014).

Dessa forma, o aproveitamento de ambas frações resultantes da carbonização hidrotérmica do bagaço de malte evidencia a necessidade de mais estudos na área, buscando tornar este processo viável economicamente.

\section{3 Ácido Lático}

O ácido lático (ácido 2-hidroxipropanóico) é um composto orgânico bastante versátil utilizado nas indústrias alimentícias, farmacêuticas, químicas, têxteis, cosméticas, entre outras, podendo ser obtido química ou bioquimicamente (MUSSATTO et al., 2008), porém as rotas bioquímicas apresentam-se como sendo mais sustentáveis e favoráveis ao meio ambiente (GREWAL; KHARE, 2018). Sua demanda vem crescendo consideravelmente nos últimos anos por conta de sua aplicação na produção de um biopolímero multifuncional conhecido como ácido polilático (PLA), o qual é uma alternativa sustentável em relação ao uso de polímeros de origem não renovável (GREWAL; KHARE, 2018; JIANG et al., 2019; KOMESU et al., 2017; OUYANG et al., 2013).

Sua produção utilizando biomassa como matéria-prima é conduzida a partir de rotas bioquímicas. Primeiramente, faz-se necessário um processo de pré-tratamento para liberação da celulose contida na matriz lignocelulósica, seguido de hidrólise deste polímero para liberação dos monômeros de glicose no meio, estes que são o substrato utilizado pelos microrganismos fermentadores que produzem o ácido lático. Nesse tipo de aplicação, os microrganismos utilizados são os dos gêneros
Lactobacillus e Bacillus. (GREWAL; KHARE, 2018; JIANG et al., 2019; KOMESU et al., 2017; MUSSATTO et al., 2007, 2008; OUYANG et al., 2013), apresentando rendimentos de até 95\% para conversão de hidrolisados lignocelulósicos (WEE; RYU, 2009). Pelos altos custos das principais matérias-primas utilizadas como fontes de carbono na produção do ácido lático (glicose, sacarose e amido), muitas vezes a produção desse composto não é economicamente viável (JIANG et al., 2019; MUSSATTO et al., 2007; OUYANG et al., 2013).

Desta forma, bagaço de malte apresenta-se como uma matéria-prima com potencial para esta aplicação por apresentar teores de celulose (glicose) significativos, de acordo com os resultados deste trabalho, de Mussatto e Roberto (2016) e de Qin et al. (2018), obtendo valores de $15,99 \%, 16,78 \%$ e $20,56 \%$, respectivamente; por ser gerado em grande quantidade nas indústrias cervejeiras e, principalmente, por ser uma matériaprima de baixo custo, assim como a maioria das biomassas lignocelulósicas, o que pode impactar diretamente na viabilidade da produção do ácido lático.

\subsection{5-hidroximetilfurfural (HMF)}

O 5-hidroximetilfurfural, ou HMF, é um composto orgânico formado por um anel furânico com a presença de dois grupos funcionais: aldeído e álcool, como ilustrado na Figura 2. Sua obtenção se dá a partir da desidratação de carboidratos constituídos por 6 carbonos, sendo os principais a frutose, que é mais reativa e oferece maiores rendimentos, em média, do que outras hexoses, e a glicose (HEO et al., 2019; WANG et al., 2014). Ele pode ser convertido a diversos produtos químicos, como o 2,5-dimetiltetrahidrofurano (DMTHF), o 2,5dimetilfurano (DMF), o ácido levulínico, o álcool furfurílico, entre outros (LI et al., 2019; NGUYEN et al., 2016), sendo um importante precursor para produtos mais complexos utilizado nas indústrias farmacêuticas, agroquímicas, de cosméticos e de biocombustíveis, por exemplo (HEO et al., 2019).

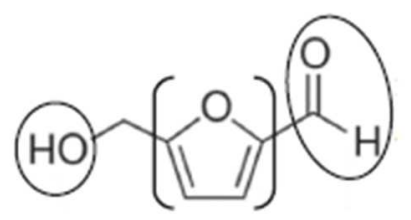

\section{Figura 2 - Estrutura química do 5-hidroximetilfurfural.}

\section{Fonte: Adaptado de HEO et al., 2019.}

Sua produção a partir de biomassa lignocelulósica é conduzida a partir das etapas de pré-tratamento, para liberação dos polímeros de celulose da matriz lignocelulósica, e de hidrólise, para quebra das ligações entre os monômeros de glicose e consequente liberação dos mesmos no meio reacional. Em seguida, ocorre a reação de desidratação de tais hexoses para sua formação. Para se alcançar rendimentos satisfatórios (acima de 70\%), são utilizados catalisadores do tipo ácido de Brønsted ou de Lewis, principalmente os de fórmula $\mathrm{CrCl}_{\mathrm{x}}$ (NGUYEN et al., 2016; WANG et al., 2014).

Diversas biomassas lignocelulósicas já foram estudadas como matérias-primas para a geração de HMF, como a madeira de pinheiro, a palha de arroz, os resíduos da colheita de milho (HEO et al., 2019) e o bagaço de cana (IRYANI et al., 2013). Não existem estudos na literatura sobre esta aplicação utilizando o bagaço de malte, porém, por sua similaridade em composição química com algumas das biomassas citadas, especialmente, 
não madeiras, pode-se inferir que este resíduo se apresenta como uma fonte promissora.

\subsection{Nutrição humana}

O aumento da demanda por proteínas vem crescendo consideravelmente nos últimos anos devido ao crescimento populacional e à urbanização, o que impulsiona o desenvolvimento de pesquisas para que se consiga obtê-las em maior quantidade (QIN et al., 2018). Por possuir teor considerável de proteínas em sua composição, uma forma de agregar valor ao bagaço de malte seria por meio do isolamento e do aproveitamento destas como base para a suplementação humana. Ainda haveria uma maior utilização e um melhor aproveitamento dessa matéria-prima.

Porém, na literatura consultada, nenhuma tecnologia de separação das proteínas desenvolvidas até hoje apresentou-se como viável economicamente numa escala comercial, visto que os processos de secagem e de extração (produtos químicos e enzimas) são muito dispendiosos e a eficiência da separação não é alta o suficiente, o que confere barreiras à esta aplicação (HE et al., 2019).

Apesar da dificuldade para isolamento das proteínas, estas podem ser aproveitadas, juntamente com as fibras, na alimentação humana, por meio da adição do material in natura ou em forma de farinha a alimentos do cotidiano, como barras de cereal e biscoitos, obtendo produtos com elevado valor nutricional quando comparados a produtos comerciais (BARTZ et al., 2007; STOJCESKA et al., 2008). Stojceska et al. (2008) avaliaram o efeito da adição de bagaço de malte seco e moído como ingrediente para biscoitos, encontrando que até $30 \%$ de bagaço de malte possibilitou produtos com características físico-químicas aceitáveis, porém o teor de $20 \%$ foi mais recomendado por proporcionar características mais próximas às dos produtos comerciais.(KHAN et al., 2019)

\section{CONCLUSÃO}

A partir das análises realizadas, foi possível caracterizar quimicamente o bagaço de malte estudado, alcançando $99,96 \%$ de sua composição, em base seca, sendo os resultados obtidos para cada componente similares aos encontrados em outros estudos. A necessidade de correção do teor de extrativos para extração das hordeínas evidenciou que o uso de etanol $80 \% \mathrm{v} / \mathrm{v}$ como solvente extrator em materiais ricos em proteínas não é adequado, sendo interessante substituí-lo na metodologia de determinação dos extrativos ou realizar testes de teores de proteínas nos materiais com e sem extrativos e determinar o teor real de extrativos, como feito neste trabalho.

A composição química encontrada evidencia a possibilidade de uso do bagaço de malte como matéria-prima em diferentes processos, seja para produção de biocombustíveis ou de compostos químicos de alto valor agregado em nível comercial. Entre as potenciais aplicações, foram abordados os usos para produção de etanol de segunda geração; de biocarvões e de ácidos orgânicos por carbonização hidrotérmica; de 5hidroximetilfurfural (HMF); de ácido lático e, ainda, de suplementos que podem ser utilizados na nutrição humana.

\section{AGRADECIMENTOS}

Este trabalho foi realizado com apoio da Fundação de Amparo à Pesquisa do Estado de Minas Gerais (FAPEMIG), da Coordenação de Aperfeiçoamento Pessoal de Nível Superior (CAPES) e da Universidade Federal de Viçosa (UFV). Os autores agradecem aos professores e técnicos do Departamento de Química, do Departamento de Bioquímica e Biologia Molecular e do Departamento de Solos da Universidade Federal de Viçosa, pelo suporte dado ao longo do estudo, e à Cervejaria Wegas Bier, pela cessão do material estudado.

\section{R E F E R Ê N C I A S}

ALIYU, S.; BALA, M. Brewer's spent grain: A review of its potentials and applications. African Journal of Biotechnology, v. 10, n. 3, p. 324-331, 2011.

ANDRADE, R. B.; OLIVEIRA, T. C.; KICH, J. N. Determinação de Nitrogênio Total em Leite e derivados Lácteos pelo método de Micro-Kjedahl (MET POA/11/02/01). Laboratório Nacional Agropecuário LANAGRO/RS, p. 8, 2013.

BARTZ, G. L.; FREITAS, J.; MACHADO, A. Elaboração e caracterização de barras de cereais elaboradas com resíduo sólido de cervejaria. p. 0-4, 2007.

BIOFLEX. Bioflex I: Produção de Biocombustível. Disponível em: <https://bit.ly/2ryydyy>. Acesso em: 10 dez. 2019.

BOYER, L. J. et al. The effects of furfural on ethanol production by saccharomyces cereyisiae in batch culture. Biomass and Bioenergy, v. 3, n. 1, p. 41-48, 1992.

BRUST, L. A. C. et al. Enfermidades em Bovinos Associadas ao Consumo de Resíduos de Cervejaria. Pesquisa Veterinaria Brasileira, v. 35, n. 12, p. 956-964, 2015.

CERVBRASIL. Anuário da cerveja no Brasil - 2016. Disponível em: <www.cervbrasil.org.br/novo_site/anuarios/CervBrasilAnuario2016_WEB.pdf>. Acesso em: 15 set. 2019.

DRAPCHO, C. M.; NHUAN, N. P.; WALKER, T. H. Biofuels Engineering Process Technology. 1. ed. [s.1.] McGrawHill, 2008.

GOLDSHMID, O. Lignins: Ocurrence, formation, structure and reactions. In: SARKANEN, K. V.; LUDWIG, C. H. (Eds.). . Lignins: Ocurrence, formation, structure and reactions. New York: Wiley-Interscience, 1971. p. 241266.

GOMES, J. R. Usina de E2G da Raízen deve atingir capacidade máxima em 2019/20.

GOMIDE, J. L.; DEMUNER, B. J. Determinação do teor de lignina em material lenhoso método klason modificado. O Papel, v. 47, n. January 1986, p. 36-38, 1986.

GONÇALVES, L. C.; BORGES, I.; FERREIRA, P. D. S. Alimentação de Gado de Leite. 1. ed. Belo Horizonte: FEPMVZ, 2009.

GREWAL, J.; KHARE, S. K. One-pot bioprocess for lactic acid 
production from lignocellulosic agro-wastes by using ionic liquid stable Lactobacillus brevis. Bioresource Technology, v. 251, n. November 2017, p. 268-273, 2018.

HE, Y. et al. Wet fractionation process to produce high protein and high fiber products from brewer's spent grain. Food and Bioproducts Processing, v. 117, p. 266-274, 2019.

HEO, J. B.; LEE, Y. S.; CHUNG, C. H. Raw plant-based biorefinery: A new paradigm shift towards biotechnological approach to sustainable manufacturing of HMF. Biotechnology Advances, v. 37, n. 8, p. $107422,2019$.

IRYANI, D. A. et al. Production of 5-hydroxymethyl Furfural from Sugarcane Bagasse under Hot Compressed Water. Procedia Earth and Planetary Science, v. 6, n. May 2014, p. 441-447, 2013.

JIANG, S.; XU, P.; TAO, F. 1-Lactic acid production by Bacillus coagulans through simultaneous saccharification and fermentation of lignocellulosic corncob residue. Bioresource Technology Reports, v. 6, n. January, p. $131-137,2019$

KHAN, T. A. et al. Hydrothermal carbonization of lignocellulosic biomass for carbon rich material preparation: A review. Biomass and Bioenergy, v. 130, n. August, p. 105384, 2019.

KIRIN HOLDINGS COMPANY. Kirin Beer University Report Global Beer Production by Country in 2016. Disponível em: <https://www.kirinholdings.co.jp/english/news/2017/08 10_01.html>. Acesso em: 15 set. 2019.

KOMESU, A. et al. Lactic Acid Production to Purification: A Review. BioResources, v. 12, n. 2, p. 4364-4383, 2017.

KUNZE, W. Technology Brewing and Malting. 5. ed. Berlin: VLB Berlin, 2014.

LI, X. et al. Production of 5-hydroxymethylfurfural and levulinic acid from lignocellulosic biomass and catalytic upgradation. Industrial Crops and Products, v. 130, n. September 2018, p. 184-197, 2019.

LINSKENS, H. F.; JACKSON, J. F. Modern Methods of Plant Analysis: Beer Analysis. 1. ed. Berlin: Springer-Verlag, 1988.

MARCUSSO, E. F.; MÜlLER, C. V. ANUÁRIO DA CERVEJA NO BRASIL 2018: Crescimento e Inovação. Ministério da Agricultura, Pecuária e Abastecimento, n. 72 , p. 6, 2019.

MOLINA-CANO, J. L. et al. Relationships between barley hordeins and malting quality in a mutant of cv. Triumph I. Genotype by environment interaction of hordein content. Journal of Cereal Science, v. 34, n. 3, p. 285 294, 2001

MUSSATTO, S. I. et al. Brewer's spent grain as raw material for lactic acid production by Lactobacillus delbrueckii. Biotechnology Letters, v. 29, n. 12, p. 1973-1976, 2007.

MUSSATTO, S. I. et al. Effects of medium supplementation and $\mathrm{pH}$ control on lactic acid production from brewer's spent grain. Biochemical Engineering Journal, v. 40, n. 3, p.
437-444, 2008.

MUSSATTO, S. I.; DRAGONE, G.; ROBERTO, I. C. Brewers' spent grain: Generation, characteristics and potential applications. Journal of Cereal Science, v. 43, n. 1, p. 1-14, 2006.

MUSSATTO, S. I.; ROBERTO, I. C. Chemical characterization and liberation of pentose sugars from brewer's spent grain. Journal of Chemical Technology and Biotechnology, v. 81, n. 3, p. 268-274, 2006.

NGUYEN, C. VAN et al. Combined treatments for producing 5-hydroxymethylfurfural (HMF) from lignocellulosic biomass. Catalysis Today, v. 278, p. 344-349, 2016.

OUYANG, J. et al. Open fermentative production of 1-lactic acid by Bacillus sp. strain NL01 using lignocellulosic hydrolyzates as low-cost raw material. Bioresource Technology, v. 135, p. 475-480, 2013.

PALMQVIST, E.; HAHN-HÄGERDAL, B. Fermentation of lignocellulosic hydrolysates. II: Inhibitors and mechanisms of inhibition. Bioresource Technology, v. 74, n. 1, p. 25-33, 2000.

PARPINELLI, W. Utilização de resíduo seco de cervejaria na alimentação de frangos de corte. Dois Vizinhos: Universidade Tecnológica Federal do Paraná, 2016.

PINHEIRO, T. et al. Intensifying ethanol production from brewer's spent grain waste: Use of whole slurry at high solid loadings. New Biotechnology, v. 53, n. April 2018, p. 1-8, 2019.

POERSCHMANN, J. et al. Characterization of biocoals and dissolved organic matter phases obtained upon hydrothermal carbonization of brewer's spent grain. Bioresource Technology, v. 164, p. 162-169, 2014.

POERSCHMANN, J. et al. Organic breakdown products resulting from hydrothermal carbonization of brewer's spent grain. Chemosphere, v. 131, p. 71-77, 2015.

QIN, F.; JOHANSEN, A. Z.; MUSSATTO, S. I. Evaluation of different pretreatment strategies for protein extraction from brewer's spent grains. Industrial Crops and Products, v. 125, n. June, p. 443-453, 2018.

RAVINDRAN, R. et al. A comparative analysis of pretreatment strategies on the properties and hydrolysis of brewers' spent grain. Bioresource Technology, v. 248, p. 272279, 2018.

REINOLD, M. R. Manual Prático de Cervejaria. 1. ed. São Paulo: ADEN Editora e Comunicações Ltda, 1997.

SGARBIERI, V. C. Proteínas em Alimentos Protéicos: Propriedades, Degradações, Modificações. 1. ed. São Paulo: Livraria Varela, 1996.

SLUITER, A. et al. Determination of Ash in Biomass: Laboratory Analytical Procedure (LAP) (NREL / TP510-42622). National Renewable Energy Laboratory (NREL), p. 8, 2008a.

SLUITER, A. et al. Determination of Extractives in Biomass: Laboratory Analytical Procedure (LAP) (NREL/TP-51042619). National Renewable Energy Laboratory (NREL), p. 12, 2008b. 
SLUITER, A. et al. Determination of structural carbohydrates and lignin in biomass: Laboratory Analytical Procedure (LAP) (NREL/TP-510-42618). National Renewable Energy Laboratory (NREL), p. 17, 2012.

STOJCESKA, V. et al. The recycling of brewer's processing byproduct into ready-to-eat snacks using extrusion technology. Journal of Cereal Science, v. 47, n. 3, p. 469-479, 2008.

WANG, T.; NOLTE, M. W.; SHANKS, B. H. Catalytic dehydration of $\mathrm{C} 6$ carbohydrates for the production of hydroxymethylfurfural (HMF) as a versatile platform chemical. Green Chemistry, v. 16, n. 2, p. 548-572, 2014
WEE, Y.; RYU, H. Bioresource Technology Lactic acid production by Lactobacillus sp . RKY2 in a cell-recycle continuous fermentation using lignocellulosic hydrolyzates as inexpensive raw materials. Bioresource Technology, v. 100, n. 18, p. 4262-4270, 2009.

WILKINSON, S.; SMART, K. A.; COOK, D. J. A comparison of dilute acid- and alkali-catalyzed hydrothermal pretreatments for bioethanol production from brewers' spent grains. Journal of the American Society of Brewing Chemists, v. 72, n. 2, p. 143-153, 2014. 